\title{
Association of Dyslipidemia and Comorbidities with Risk Factors Among Diabetic Patients: A Retrospective Analysis
}

This article was published in the following Dove Press journal: Diabetes, Metabolic Syndrome and Obesity: Targets and Therapy

\author{
Zohair Jamil Gazzaz' \\ Rahila Iftikhar ${ }^{2}$ \\ Tahir Jameel' \\ Mukhtiar Baig $\mathbb{D}^{3}$ \\ Manal Abdulaziz Murad (D) ${ }^{2}$ \\ 'Department of Internal Medicine, \\ Faculty of Medicine, Rabigh, King \\ Abdulaziz University, Jeddah, Saudi \\ Arabia; ${ }^{2}$ Department of Family Medicine, \\ Faculty of Medicine, King Abdulaziz \\ University, Jeddah, Saudi Arabia; \\ ${ }^{3}$ Department of Clinical Biochemistry, \\ Faculty of Medicine, Rabigh, King \\ Abdulaziz University, Jeddah, Saudi Arabia
}

Correspondence: Rahila Iftikhar Department of Family Medicine, Faculty of Medicine, King Abdulaziz University, Jeddah 2243I, Saudi Arabia

Tel + I346754I966

Email rahila_iftikhar@hotmail.com
Purpose: To find out the association of dyslipidemia and comorbidities with risk factors among type-2 diabetes mellitus (T2DM) patients attending King Abdulaziz University Hospital (KAUH) Jeddah, Saudi Arabia (SA).

Patients and Methods: Three hundred and twenty-five T2DM patients were enrolled from the electronic record of the KAUH. The patients' existing comorbidities and dyslipidemia correlation with demographic, clinical, and available laboratory data were sought. Statistical analysis was performed on SPSS-23.

Results: Of the total $325 \mathrm{~T} 2 \mathrm{DM}$ patients with a mean age of $60.13 \pm 10.5$ years [males 95 (29.23\%) and females $230(70.77 \%)]$ were included from the electronic record. Poor glycemic control was observed in 222 (68.31\%) subjects (HbAlc > 7\%), and 154 $(47.39 \%)$ subjects had DM for more than ten years. Among our study subjects, 103 (31.69\%) were hypertensive (HTN), 112 (34.46\%) had ischemic heart disease (IHD), 45 $(13.85 \%)$ were obese, $8(2.46 \%)$ had a stroke and $269(82.77 \%)$ had dyslipidemia. Of the total 269 dyslipidemic patients, 168 (62.45\%) were on hypolipidemic treatment. On comparison of study variables according to dyslipidemia versus normal lipid levels, the lipid profile, including HDLc, LDLc, TC, and TG, revealed a highly significant difference (p-value $<0.001$ ) whereas many variables were not significantly different. HBA1c, FBG, and RBG were significantly higher in dyslipidemic subjects. Logistic regression analysis of risk factors and comorbidities in our patients revealed that age 60-69 years and 70-79 years had a significant association with comorbidities. Similarly, logistic regression analysis of risk factors and dyslipidemia in our patients revealed no statistically significant association.

Conclusion: Our results observed that the comorbidities were associated with increasing age and common comorbidities were HTN, IHD, dyslipidemia. Our study has highlighted the current trends in T2DM symptomatology and comorbidities. Efficient management and control by early screening and developing healthy lifestyles in our patients can be very helpful in the prevention of all these highly morbid complications of this preventable disease.

Keywords: dyslipidemia, DM, IHD, cholesterol, comorbidities, HbA1c, hypertension

\section{Introduction}

Diabetes mellites (DM) being a metabolic disorder presenting mostly with hyperglycemia due to either relative or absolute deficiency of insulin. The world over there is a progressive rise in the number of patients of DM. It is estimated that around 350 million people would be diabetic by year 2030. ${ }^{1}$ According to a WHO report, 
DM is ranked to be the potential seventh leading cause of death by the next ten years. Diabetic complications are seen in around $66 \%$ of patients of long-standing DM. Lifestyle in Saudi Arabia is changing so rapidly that according to a recent study, the incidence of obesity has been reported to be around $54 \%$ in the adult population of Saudi Arabia. ${ }^{2}$ A Saudi Arabia study published in 2017 reported the incidence of type II DM from $17.7-25.7 \%$ in adults with more incidence in females. ${ }^{3}$ Saudi Arabia is having the highest prevalence of DM in the Middle east. ${ }^{4}$ A large number of complications have long been associated with DM, including disturbed cholesterol metabolism, hypertension, cardiac complications, retinal and renal disorders, and peripheral neuropathies. In 2015, DM \& its complications resulted in more than one million deaths. ${ }^{5}$

Increased risk of heart diseases is mostly associated with dyslipidemias leading to atherosclerosis. ${ }^{6}$ Myocardial infarction due to coronary atherosclerosis has been mentioned as a leading cause of mortality in almost $80 \%$ of diabetics, the world over. ${ }^{7}$ The patients of T2DM often have other metabolic derangements resulting in enhanced morbidity and mortality. ${ }^{8}$

Comorbidity, by definition, is the occurrence of multiple chronic disorders in the same person due to one index disease is commonly seen in DM. Multiple diseases adversely affect the quality of life of an individual, and the patient has got an overall depressive element. ${ }^{9}$ The occurrence of multiple health-related problems in an individual poses a heavy burden on the individual, family, and the healthcare providing system of the society. Only a few studies have been carried out in Saudi Arabia regarding this aspect of the disease, and we hope that our effort would be helpful in raising the concern and awareness against this disease. ${ }^{10,11}$ The present study aimed to find out the association of dyslipidemia and comorbidities with risk factors among T2DM patients attending KAUH, Jeddah, SA.

\section{Materials and Methods}

This retrospective study was conducted from Feb 2017 to March 2018 at the KAUH, Jeddah, SA. All the T2DM patients were included in the study were selected from their electronic record and patients suffering from Type1DM were not included in the study as the comorbidities and complications of Type $1 \mathrm{DM}$ are different from T2DM. Relevant records were obtained from the hospital's central electronic medical records for clinical data and relevant investigative findings. For this study, permission was granted by the Ethics Research Committee at KAU, Jeddah (Reference No. 373-18). Being a retrospective nature of the study, the consent of the patient was waived by the committee and we also maintained the confidentiality of all the patients. All the procedures and measures were in accordance with the international ethical standards and the latest (2008) version of the Helsinki Declaration of 1975.

The data regarding the type of DM, age, gender, BP, weight, height, educational level, FBG, RBG, lipid profile, serum creatinine, HbA1c values, complications, and associated problems were noted. Family history of dyslipidemia was not found in their record. All the biochemical investigations were done at KAUH laboratory by using kits. In our study only those patients were included who were taking anti-diabetic treatment excluding insulin and for selecting patients "American Diabetes Association (ADA) criteria (FBG $\geq 126 \mathrm{mg} / \mathrm{dL}, \mathrm{HbA} 1 \mathrm{C} \geq 6.5 \%$, or $\mathrm{RBG} \geq 200 \mathrm{mg} / \mathrm{dL}$ )" was followed. ${ }^{12}$ The patients we were divided into two groups according to their HbAlc values and patients having HbAlc $\leq 7$ good glycemic control, and HbAlc $>7$ poor glycemic control. ${ }^{13}$ Our study subjects were also divided into dyslipidemic and normal and for the study, dyslipidemia was considered as "having 1 or more of the following: $\mathrm{TC} \geq 5.18 \mathrm{mmol} / \mathrm{L}, \mathrm{TG} \geq 1.7 \mathrm{mmol} / \mathrm{L}, \mathrm{LDL} \geq 3.37 \mathrm{mmol} / \mathrm{L}$ or HDL $\leq 1.04 \mathrm{mmol} / \mathrm{L} . "{ }^{, 14}$ The MI was diagnosed from the patients' medical records and confirmed by the treating physician. The ADA criterion was used to diagnose hypertension among T2DM subjects, i.e., SBP $\geq 140 \mathrm{mmHg}$ and DBP $\geq 90 \mathrm{mmHg}$ measured on multiple visits. ${ }^{15}$

All biochemical parameters were determined in the KAUH biochemistry laboratory. The blood glucose, lipid profile serum creatinine, and $\mathrm{HbA1c}$ levels were investigated on an autoanalyzer (Roche Modular P-800, Roche Diagnostics, Germany).

\section{Statistical Analysis}

Analysis of study data was performed by SPSS (Statistical Package for Social Sciences) version 23. Mean \pm SD was mentioned for quantitative values. Frequency and percentages were mentioned for qualitative variables. The Student's $t$-test was used to compare the mean of age, BMI, systolic \& diastolic BP (mm Hg), HDLc, LDLc, TG, serum creatinine, HBA1c, random and fasting blood glucose between dyslipidemia and non-dyslipidemic diabetic patients. The logistic regression analysis was also done to find out the association between variables. A p-value $\leq 0.05$ was considered as significant.

\section{Results}

Our study cohort included 325 patients of T2DM with a mean age of $60.13 \pm 10.5$ years [males 95 (29.23\%) and 
females $230(70.77 \%)]$. Poor glycemic control was observed in $222(68.31 \%)$ subjects (HbAlc > 7\%), and 154 (47.39\%) subjects had DM for more than ten years. Among our study subjects, 103 (31.69\%) were hypertensive (HTN), 112 (34.46\%) had ischemic heart disease (IHD), $45(13.85 \%)$ were obese, $8(2.46 \%)$ had a stroke, and $269(82.77 \%)$ had dyslipidemia. Of the total 269 dyslipidemic patients, $168(62.45 \%)$ were on hypolipidemic treatment. Most of the participants 214 (67.3\%), were non-Saudi. The study subjects belonged to different educational background and age categories (Table 1). On comparison of study variables according to dyslipidemia versus normal lipid levels, the lipid profile, including HDLc, LDLc, TC, and TG revealed a highly significant difference ( $p$-value $<0.001$ ) whereas many variables like age, BP, serum creatinine were not significantly different. HBA1c, FBG, and RBG were significantly higher in dyslipidemic subjects (Table 2). Logistic regression analysis of risk factors and comorbidities in our patients revealed that age 60-69 years and 70-79 years had a significant association with comorbidities. Similarly, the duration of diabetes $>10$ years was significantly associated with comorbidities, but the association was lost after adjusting other factors. Females, educational levels, weight, height, blood pressure, HbA1c $>7$, dyslipidemia, and hypolipidemic treatment had no significant relationship with comorbidities (Table 3). Similarly, logistic regression analysis of risk factors and dyslipidemia in our patients revealed no statistically significant association (Table 4).

\section{Discussion}

The T2DM patients expect to experience several life-threating and debilitating complications throughout the world, including SA. ${ }^{16}$ Lack of proper diabetic control and chronicity of the disease, are the main aggravating factors of these complications. The simultaneous presence of two or more complications, i.e., comorbidity, produces devastation health effects because of multiple organ involvement. ${ }^{17}$ Patients' education and dedication in proper management are the key factors in better control of this potentially fatal disorder. Commitment \& willingness of health care professional has been well acknowledged in medical literature in the reduction of diabetes-related comorbidities in Saudi Arabian patients. ${ }^{18}$

In T2DM, the basic mechanism is thought to be the developing insulin resistance in the body. This mechanism leads to various derangements in the lipid metabolism resulting in various dyslipidemias. ${ }^{19}$ In our present study,
Table I Demographic, Comorbid and Essential Investigational Characteristics of Our Study Cohort

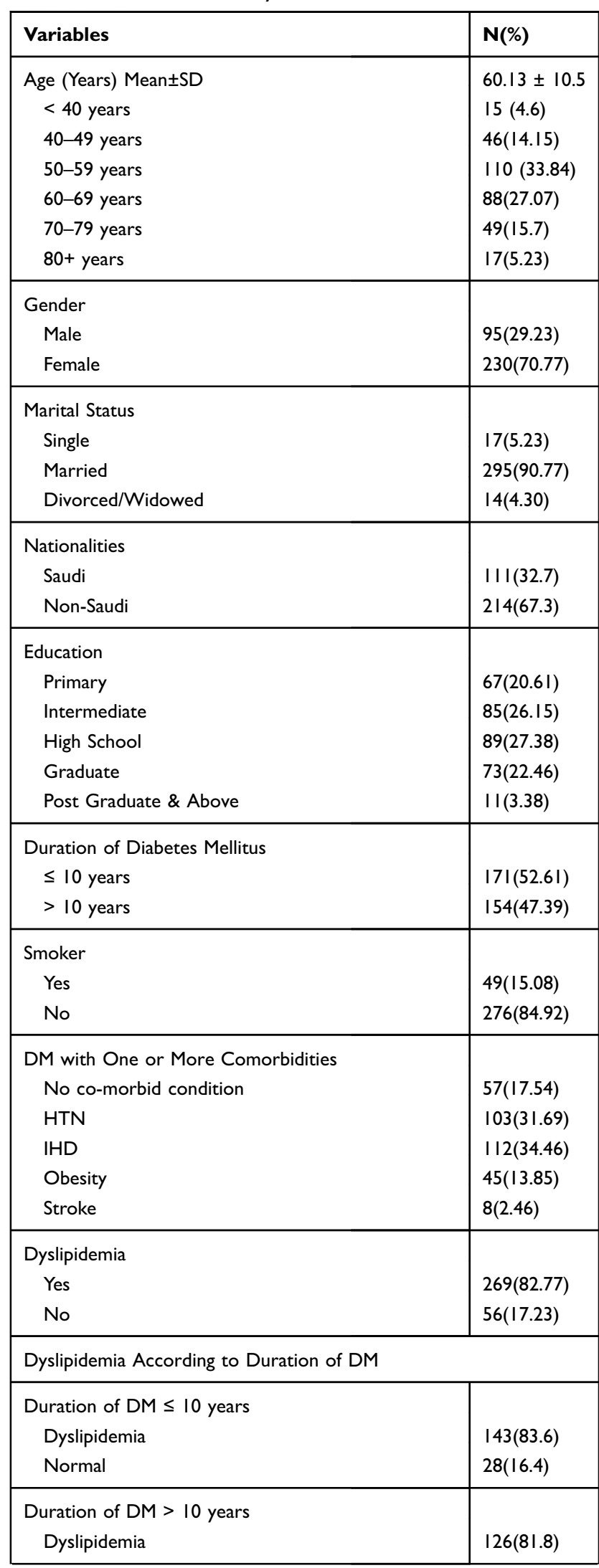

(Continued) 
Table I (Continued).

\begin{tabular}{|l|l|}
\hline Variables & $\mathbf{N}(\%)$ \\
\hline Normal & $28(I 8.2)$ \\
\hline $\begin{array}{l}\text { Dyslipidemia Treatment } \\
\text { Yes }\end{array}$ \\
No & $168(62.45)$ \\
\hline HbAlc (\%) & $101(37.55)$ \\
$\leq 7$ & \\
$>7$ & $103(31.69)$ \\
\hline
\end{tabular}

Abbreviations: HTN, hypertension; IHD, Ischemic heart disease; HbAlc, Hemoglobin Alc.

Table 2 Comparison of Study Variables According to Dyslipidemia and Normal Lipid Values

\begin{tabular}{|c|c|c|c|}
\hline Variables & $\begin{array}{l}\text { Dyslipidemia } \\
N=269\end{array}$ & $\begin{array}{l}\text { Normal } \\
\mathbf{N}=56\end{array}$ & p-value \\
\hline Age (years) & $60.12 \pm 10.6$ & $59.83 \pm 10.5$ & 0.85 \\
\hline BMI $\left(\mathrm{Kg} / \mathrm{m}^{2}\right)$ & $32.2 \pm 6.5$ & $30.7 \pm 6.3$ & 0.12 \\
\hline Systolic BP (mm Hg) & $138.7 \pm 24.7$ & $136.6 \pm 25.8$ & 0.59 \\
\hline Diastolic BP $(\mathrm{mm} \mathrm{Hg})$ & $73.0 \pm 12.8$ & $70.9 \pm 11.3$ & 0.27 \\
\hline $\mathrm{HDL}(\mathrm{mmol} / \mathrm{l})$ & $0.99 \pm 0.31$ & $1.3 \pm 0.26$ & $<0.001$ \\
\hline LDL (mmol/l) & $3.3 \pm 0.8$ & $2.1 \pm 0.3$ & $<0.001$ \\
\hline Cholesterol $(\mathrm{mmol} / \mathrm{l})$ & $5.1 \pm 1.1$ & $3.51 \pm 0.3$ & $<0.001$ \\
\hline $\mathrm{TG}(\mathrm{mmol} / \mathrm{l})$ & $2.31 \pm 1.1$ & $1.3 \pm 0.3$ & $<0.001$ \\
\hline $\begin{array}{l}\text { Serum creatinine } \\
(\mu \mathrm{mol} / \mathrm{L})\end{array}$ & $67.1 \pm 21.9$ & $68.6 \pm 26.6$ & 0.654 \\
\hline HB AIC (\%) & $8.2 \pm 1.9$ & $6.8 \pm 1.6$ & $<0.001$ \\
\hline FBG (mmol/l) & $8.1 \pm 2.7$ & $7.3 \pm 1.9$ & 0.035 \\
\hline $\mathrm{RBG}(\mathrm{mmol} / \mathrm{l})$ & $11.3 \pm 4.3$ & $9.6 \pm 3.4$ & 0.005 \\
\hline
\end{tabular}

Abbreviations: BMI, body mass index; HDLc, high-density lipoprotein cholesterol; LDLc, low-density lipoprotein cholesterol; TC, total cholesterol; TG, triglyceride; $\mathrm{HbAlc}$, Hemoglobin Alc; FBG, fasting blood glucose; RBG, random blood glucose.

we included Type II diabetic patients, both the Saudi nationals and expatriates, most of whom are working here in different capacities. Most of the participants 214 $(67.3 \%)$ were non-Saudi and about one-third of our subjects were Saudi Arabian origin, whereas $52 \%$ of them belonged to nearby Middle Eastern countries and 14.7\% from African origin. The recent studies in KSA, when examining the comorbidities in diabetic patients, have a similar multinational distribution of patients. ${ }^{20,21}$

As per the general age group involved in T2DM, almost all our patients (95.4\%) were 40 plus, with nearly $61 \%$ in $50-69$-years of age group. In our study, for diabetic patients, the odds of having comorbidities are 7.33 and 20.14 times higher in the age group 60-69 years and 70-79 years, respectively, as the odds for age less than 40 years having comorbidities. This OR remained significant after adjusting other risk factors. We do not find any proper explanation for this high OR value in this age group. Nevertheless, the possible reason for this association could be that with increasing age, all other body systems weaken, and the person is prone to develop comorbidities. Moreover, in diabetic subjects with increasing age, diabetic complications also appear. Alzaheb \& Altemani mentioned similar age group experiences of T2DM in Gulf countries and especially in SA. ${ }^{22}$ Chronicity of the disease is well associated with increasing age in diabetic patients and being a multi-disciplinary disease, mostly comorbidities are observed in varying proportions. We also found that dyslipidemia was associated with the duration of the DM. It can be explained that with increasing duration of T2DM, the insulin resistance increases, and that consequently influences carbohydrate and lipid metabolism.

We observed comorbid conditions among HTN, IHD, and varying levels of dyslipidemias. Hussain et al mentioned adverse prognostic effects on diabetics in the case of comorbidity of HTN \& $\mathrm{ICH}^{23}$ Around $14 \%$ of the patients had coexisting obesity that further complicated the picture and SA among the countries having the highest prevalence of diabetes and obesity. ${ }^{24}$ Our study observed that the majority of the obese patients had a comorbidity of HTN, Stroke, and IHD in varying proportions and this group had HbA1c levels $>7$, showing relatively poor diabetic control.

A high incidence of MI, associated dyslipidemias, and cerebrovascular accidents (CVA) were found in our patients. CVA is otherwise well correlated with DM and hypertension. A multicenter study revealed a clear association of high morbidity and mortality due to these coexisting disorders of T2DM. ${ }^{25}$ As observed in many previous studies, we also noted the rising incidence of comorbidities in elderly patients and a positive association with the increasing age. ${ }^{26-28}$

Microvascular complications involving end artery organs like selected neuropathies, retinopathy, and nephropathies are mostly associated with long-standing hyperglycemia, especially in poorly controlled T2DM. There is a clear-cut association of hypertension, long-standing T2DM with nephropathy, incidence getting as high as $60 \%$ in patients of $\mathrm{T} 2 \mathrm{DM}$ with hypertension, while the incidence of retinopathy is higher in normotensive patients of long-standing T2DM. ${ }^{29}$ 
Table 3 Logistic Regression Analysis of Risk Factor and Comorbidities in Diabetic Patients

\begin{tabular}{|c|c|c|c|c|}
\hline Variables & $\begin{array}{l}\text { Odds Ratio ( } 95 \% \text { Confidence } \\
\text { Interval) }\end{array}$ & p-value & $\begin{array}{l}\text { Adjusted Odds Ratio (95\% } \\
\text { Confidence Interval) }\end{array}$ & p-value \\
\hline \multicolumn{5}{|l|}{ Age Group } \\
\hline$<40$ years & I & & I & \\
\hline $40-49$ years & $3.24(0.87-12.06)$ & 0.080 & $2.85(0.59-13.65)$ & 0.191 \\
\hline $50-59$ years & $2.42(0.75-7.8 \mathrm{I})$ & 0.140 & $2.54(0.60-10.64)$ & 0.204 \\
\hline $60-69$ years & $7.33(2.02-26.66)$ & 0.002 & 8.35 (1.59-43.97) & 0.012 \\
\hline 70-79 years & $20.14(3.38-120.22)$ & 0.001 & $16.97(2.05-140.2)$ & 0.009 \\
\hline $80+$ years & $5.14(0.8 I-32.77)$ & 0.083 & $3.85(0.46-32.11)$ & 0.212 \\
\hline \multicolumn{5}{|l|}{ Gender } \\
\hline Male & I & & I & \\
\hline Female & $1.06(0.56-2.02)$ & 0.852 & $0.70(0.27-1.84)$ & 0.467 \\
\hline \multicolumn{5}{|l|}{ Educational Level } \\
\hline Primary & I & & I & \\
\hline Intermediate & $0.64(0.23-1.79)$ & 0.396 & $0.76(0.22-2.59)$ & 0.661 \\
\hline High School & $0.55(0.22-1.52)$ & 0.251 & $1.23(0.34-4.44)$ & 0.748 \\
\hline Graduate & $0.35(0.13-0.96)$ & 0.040 & $0.65(0.19-2.24)$ & 0.494 \\
\hline Post graduate \& above & $0.36(0.06-2.20)$ & 0.269 & $0.5 \mathrm{I}(0.06-4.44)$ & 0.540 \\
\hline Height & $0.047(0.002-1.199)$ & 0.064 & $0.02(0.00-2.75)$ & 0.117 \\
\hline Weight & $1.00(0.99-1.03)$ & 0.627 & $1.03(1.00-1.05)$ & 0.049 \\
\hline Systolic BP & $1.00(0.99-1.01)$ & 0.991 & $0.99(0.97-1.01)$ & 0.328 \\
\hline Diastolic BP & $0.99(0.97-1.01)$ & 0.989 & $1.00(0.97-1.04)$ & 0.863 \\
\hline \multicolumn{5}{|l|}{$\mathrm{HbAlc}$} \\
\hline$\leq 7$ & 1 & & 1 & \\
\hline$>7$ & $0.68(0.35-1.32)$ & 0.256 & $0.50(0.21-1.17)$ & 0.111 \\
\hline \multicolumn{5}{|l|}{ Duration of DM } \\
\hline$\leq 10$ years & 1 & & I & \\
\hline$>10$ years & $2.11(1.15-3.89)$ & 0.017 & $1.60(0.7 \mid-3.62)$ & 0.258 \\
\hline \multicolumn{5}{|l|}{ Dyslipidemia } \\
\hline No & I & & 1 & \\
\hline Yes & $1.17(0.55-2.52)$ & 0.680 & $1.33(0.58-3.08)$ & 0.500 \\
\hline \multicolumn{5}{|l|}{ Hypolipidemic Treatment } \\
\hline No & 1 & & I & \\
\hline Yes & 0.91 (0.47-1.77) & 0.773 & $0.89(0.43-1.84)$ & 0.744 \\
\hline
\end{tabular}

Notes: ${ }^{a}$ Odds ratios were adjusted for age, gender, BP, weight, height and educational level, HbAlc, duration of diabetes, dyslipidemia and hypolipidemic treatment.

We compared multiple important variables in our cohort presenting with dyslipidemia with the T2DM patients do not have dyslipidemia. There was a significant difference in tests of the lipid profile series, ie, HDLc, LDLc, TC, and TG between the groups. The HbA1c, FBG, RBG values were significantly high in the dyslipidemic individuals. The probable reason for these differences could be the deranged metabolism of the lipids and carbohydrates among such patients. The T2DM is a metabolically complex situation, varied findings have been mentioned by Fung et al. ${ }^{30}$
Our study provides a comparison of a multimorbid population of SA. Our study cohort belonged to SA and many neighboring countries having quite varied living setups. The health system is SA provides efficient care to the patients presenting with a chronic disorder like T2DM. Provision of better health care and awareness campaigns for the patients having a chronic disorder like T2DM is the key factor in better care and avoidance of multiple morbidities. However, there is also a need for an extensive move for public awareness regarding the importance of healthy living styles and regular physical activities so that this deadly but potentially preventable disease could be prevented. ${ }^{31}$ 
Table 4 Logistic Regression Analysis of Risk Factor and Dyslipidemia in Diabetic Patients

\begin{tabular}{|c|c|c|c|c|}
\hline Variables & $\begin{array}{l}\text { Odds Ratio ( } 95 \% \text { Confidence } \\
\text { Interval) }\end{array}$ & p-value & $\begin{array}{l}\text { Adjusted Odds Ratio (95\% } \\
\text { Confidence Interval) }\end{array}$ & p-value \\
\hline \multicolumn{5}{|l|}{ Age Group } \\
\hline$<40$ years & 1 & & 1 & \\
\hline $40-49$ years & $0.60(0.11-3.17)$ & 0.548 & $0.62(0 . \mid I-3.5 I)$ & 0.588 \\
\hline $50-59$ years & $1.32(0.26-6.61)$ & 0.740 & $1.53(0.28-8.34)$ & 0.624 \\
\hline 60-69 years & $1.02(0.20-5.15)$ & 0.980 & $1.33(0.22-7.93)$ & 0.751 \\
\hline $70-79$ years & $0.71(0.14-3.73)$ & 0.685 & $0.83(0.13-5.42)$ & 0.843 \\
\hline $80+$ years & $1.09(0.13-9.12)$ & 0.936 & $1.51(0.16-14.78)$ & 0.721 \\
\hline \multicolumn{5}{|l|}{ Gender } \\
\hline Male & 1 & & I & \\
\hline Female & $1.29(0.67-2.48)$ & 0.444 & $1.51(0.63-3.64)$ & 0.357 \\
\hline \multicolumn{5}{|l|}{ Educational Level } \\
\hline Primary & 1 & & 1 & \\
\hline Intermediate & $0.7 \mid(0.28-1.76)$ & 0.456 & $0.54(0.20-1.49)$ & 0.234 \\
\hline High School & $0.83(0.33-2.14)$ & 0.705 & $0.63(0.21-1.85)$ & 0.396 \\
\hline Graduate & $1.22(0.44-0.3 .34)$ & 0.700 & $1.04(0.34-3.21)$ & $0.94 I$ \\
\hline Post graduate \& above & $0.50(0.09-2.93)$ & 0.442 & $0.4 \mathrm{I}(0.06-2.79)$ & 0.359 \\
\hline Height & $0.53(0.02-15.9)$ & 0.716 & $1.12(0.01-110.1)$ & 0.961 \\
\hline Weight & $1.02(0.99-1.04)$ & 0.184 & $1.02(0.99-1.04)$ & 0.200 \\
\hline Systolic BP & $1.00(0.99-1.02)$ & 0.592 & $1.00(0.99-1.02)$ & 0.897 \\
\hline Diastolic BP & $1.02(0.99-1.04)$ & 0.273 & I.0I (0.98-I.04) & 0.398 \\
\hline \multicolumn{5}{|l|}{$\mathrm{HbAlc}$} \\
\hline$\leq 7$ & I & & 1 & \\
\hline$>7$ & $1.28(0.68-2.4 I)$ & 0.446 & $1.20(0.60-2.4 I)$ & 0.600 \\
\hline \multicolumn{5}{|l|}{ Duration of DM } \\
\hline$\leq 10$ years & 1 & & I & \\
\hline 10 years & $9.94(0.52-1.73)$ & 0.852 & $0.82(0.39-1.70)$ & 0.587 \\
\hline \multicolumn{5}{|l|}{ Comorbidities } \\
\hline No & 1 & & I & \\
\hline Yes & $1.17(0.55-2.52)$ & 0.680 & $1.36(0.59-3.11)$ & 0.474 \\
\hline
\end{tabular}

Notes: a Odds ratios were adjusted for age, gender, BP, weight, height and educational level, HbAlc, duration of diabetes and comorbidities.

\section{Limitations}

Like all the retrospective studies, we received data from the central registry and did not have direct exposure to the patients. A number of questions remained unanswered like the dietary and exercise habits and management associated problems faced by elderly diabetics.

\section{Conclusion}

Our results observed that the comorbidities were associated with increasing age, and common comorbidities were HTN, IHD, dyslipidemia.

Our study has highlighted the current trends in T2DM symptomatology and comorbidities. Efficient management and control by early screening and developing healthy lifestyles in our patients can be very helpful in the prevention of all these highly morbid complications of this preventable disease.

\section{Acknowledgments}

The authors are thankful to all hospital staff that helped us in data collection.

\section{Disclosure}

The authors report no conflicts of interest in this work.

\section{References}

1. Wild S, Roglic G, Green A, et al. Global prevalence of diabetes: estimates for the year 2000 and projections for 2030. Diabetes Care. 2004;27:1047-1053. doi:10.2337/diacare.27.5.1047 
2. Al-Ghamdi S, Shubair MM, Aldiab A, et al. Prevalence of overweight and obesity based on the body mass index; a cross-sectional study in Alkharj, Saudi Arabia. Lipids Health Dis. 2018;17:134. doi:10.1186/s12944-018-0778-5

3. Alotaibi A, Perry L, Gholizadeh L, et al. Incidence and prevalence rates of diabetes mellitus in Saudi Arabia: an overview. J Epidemiol Glob Health. 2017;7:211-218. doi:10.1016/j.jegh.2017.10.001

4. International Diabetes Federation. IDF Diabetes Atlas. 6th ed ed Brussels: IDF; 2017.

5. International Diabetes Federation. Diabetes in India-2015; 2016.

6. Ghandour R, Mikki N, Rmeileh NM, et al. Complications of type 2 diabetes mellitus in Ramallah and al-Bireh: the palestinian diabetes complications and control study (PDCCS). Prim Care Diabetes. 2018;12:547-557. doi:10.1016/j.pcd.2018.07.002

7. Alatorre CI, Hoogwerf BJ, Deeg MA, et al. Factors associated with stroke, myocardial infarction, ischemic heart disease, unstable angina, or mortality in patients from real world clinical practice with newly-diagnosed type 2 diabetes and early glycemic control. Curr Med Res Opin. 2018;34:337-343. doi:10.1080/ 03007995.2017.1396969

8. Nelson AJ, Rochelau SK, Nicholls SJ. Managing dyslipidemia in type 2 diabetes. Endocrinol Metab Clin. 2018;47:153-173. doi:10.1016/j.ecl.2017.10.004

9. Fung AC, Tse G, Cheng HL, et al. Depressive symptoms, co-morbidities, and glycemic control in Hong Kong Chinese elderly patients with type 2 diabetes mellitus. Front Endocrinol. 2018;9:261. doi:10.3389/fendo.2018.00261

10. Alramadan MJ, Magliano DJ, Alhamrani HA, et al. Lifestyle factors and macro-and micro-vascular complications among people with type 2 diabetes in Saudi Arabia. Diabetes Metab Syndr. 2019;13:484-491.

11. Elbur AI, Alasseri A, Alkhaldi M, et al. Adherence to lipid lowering drugs and level of low-density lipoprotein cholesterol among patients with type 2 diabetes, King Fahd Hospital, Al Khobar, Kingdom of Saudi Arabia. J Diab Care. 2019;1:1-2

12. American Diabetes Association. Standards of medical care in diabetes 2014. Diabetes Care. 2014;37(Suppl 1):S14-S80. doi:10.2337/ dc14-S014

13. Baranwal JK, Maskey R, Majhi S, et al. Association between level of $\mathrm{HbA1c}$ and lipid profile in T2DM patients attending diabetic OPD at BPKIHS. Health Renaiss. 2017;13:16-23. doi:10.3126/hren. v13i3.17923

14. Expert Committee on the Prevention and Control of Dyslipidemia in Chinese adults. Guidelines on prevention and control of dyslipidemia in Chinese adults. Chin J Cardiol. 2007;35:5.

15. American Diabetes Association. Cardiovascular disease and risk management. Sec. 9 in standards of medical care in diabetes-2018. Diabetes Care. 2018;41(Suppl. 1):S86-S104. doi:10.2337/dc18-S009

16. Alshaya AK, Alsayegh AK, Alshaya HK, et al. The common complications and comorbidities among Saudi diabetic patients in Northern Saudi Arabia. Open $J$ Endocr Metab Dis. 2017;7:151-161. doi:10.4236/ojemd.2017.77014

17. American Diabetes Association. Diagnosis and classification of diabetes mellitus. Diabet Care. 2010;33:S62-S69. doi:10.2337/dc10S062
18. Dowell A, Stubbe M, Macdonald L, et al. A longitudinal study of interactions between health professionals and people with newly diagnosed diabetes. Ann Fam Med. 2018;16:37-44. doi:10.1370/ afm. 2144

19. Zheng Y, Ley SH, Hu FB. Global aetiology and epidemiology of type 2 diabetes mellitus and its complications. Nat Rev Endocrinol. 2018;14:88. doi:10.1038/nrendo.2017.151

20. Abdulghani HM, AlRajeh AS, AlSalman BH, et al. Prevalence of diabetic comorbidities and knowledge and practices of foot care among diabetic patients: a cross-sectional study. Diabetes Metab Syndr Obes. 2018;11:417. doi:10.2147/DMSO.S171526

21. Alkhail BA, Iftikhar R, Al Shaikh A. Use of aspirin and statin as primary prevention for cardiovascular diseases. Pak J Med Sci. 2016;32:1336-1339. doi:10.12669/pjms.326.10615

22. Alzaheb RA, Altemani AH. The prevalence and determinants of poor glycemic control among adults with type 2 diabetes mellitus in Saudi Arabia. Diabetes Metab Syndr Obes. 2018;11:15.

23. Hussain A, Ali I, Ijaz M, et al. Correlation between hemoglobin A1c and serum lipid profile in Afghani patients with type 2 diabetes: hemoglobin A1c prognosticates dyslipidemia. Ther Adv Endocrinol Metab. 2017;8(4):51-57. doi:10.1177/2042018817692296

24. Saquib J, Zaghloul MS, Mazrou A, et al. A quality assessment of clinical research on type 2 diabetes in Saudi Arabia. Scientometrics. 2018;116:2085-2096. doi:10.1007/s11192-018-2823-6

25. Al Zahidy ZA, Baeshen NR, Alzamil FO, et al. Prevalence of diabetes mellitus among patient presented in Endocrinology clinic at King Abdul-Aziz Hospital and Oncology Center - jeddah - 2014. EC Diabet Metab Res. 2017;1:2-7.

26. Werfalli M, Kassanjee R, Kalula S, et al. Diabetes in South African older adults: prevalence and impact on quality of life and functional disability-as assessed using SAGE wave 1 data. Glob Health Action. 2018;11:1449924. doi:10.1080/16549716.2018.1449924

27. Karlsen B, Rasmussen B, Oftedal B. New possibilities in life with type 2 diabetes: experiences from participating in a guided self-determination Programme in general practice. Nurs Res Prac. 2018;2018.

28. Boonsatean W, Carlsson A, Östman M, et al. Living with diabetes: experiences of inner and outer sources of beliefs in women with low socioeconomic status. Glob J Health Sci. 2016;8:200. doi:10.5539/ gjhs.v8n8p200

29. Savonitto S, Morici N, Nozza A, et al. Predictors of mortality in hospital survivors with type 2 diabetes mellitus and acute coronary syndromes. Diabetes Vascular Dis Res. 2018;15:14-23. doi:10.1177/ 1479164117735493

30. Atif M, Saleem Q, Babar Z-U-D, et al. Association between the vicious cycle of diabetes-associated complications and glycemic control among the elderly: a systematic review. Medicina. 2018;54:E73. doi:10.3390/medicina54050073

31. Mosalman Haghighi M, Mavros Y, Fiatarone Singh MA, et al. The effects of structured exercise or lifestyle behavior interventions on long-term physical activity level and health outcomes in individuals with type 2 diabetes: a systematic review, meta-analysis, and meta-regression. J Phys Act Health. 2018;15:697-707. doi:10.1123/ jpah.2017-0589

Diabetes, Metabolic Syndrome and Obesity: Targets and Therapy

Dovepress

\section{Publish your work in this journal}

Diabetes, Metabolic Syndrome and Obesity: Targets and Therapy is an international, peer-reviewed open-access journal committed to the rapid publication of the latest laboratory and clinical findings in the fields of diabetes, metabolic syndrome and obesity research. Original research, review, case reports, hypothesis formation, expert opinion and commentaries are all considered for publication. The manuscript management system is completely online and includes a very quick and fair peer-review system, which is all easy to use. Visit http://www.dovepress.com/testimonials.php to read real quotes from published authors. 